\title{
OS DESAFIOS À GESTÃO DAS CIDADES: UMA CHAMADA PARA A AÇÃO EM TEMPOS DE EMERGÊNCIA DAS CIDADES INTELIGENTES NO BRASIL.
}

\section{THE CHALLENGES TO THE CITIES MANAGEMENT: A CALL FOR ACTION IN TIMES OF THE EMERGENCE OF SMART CITIES IN BRAZIL.}

\author{
Marcos Cesar Weiss ${ }^{1}$
}

\section{Resumo}

A nova dinâmica mundial tem exigido que as cidades se voltem para as importantes questões que envolvem seu papel na cena global: incremento da competitividade dos países onde se localizam e promoção da prosperidade para seus residentes e para as organizações que nelas operam. Tendo como base uma revisão bibliográfica, esse ensaio propõe uma reflexão acerca das imperiosas ações exigidas de gestores públicos e demais atores sociais no sentido de fazer frente aos desafios interpostos às cidades para que essas possam se destacar no cenário contemporâneo em que estão presentes a intensa urbanização, a competição por mercados, o permanente e crescente surgimento de tecnologias, as exigências por desenvolvimento sustentável, por efetiva governança e por um novo paradigma para a gestão urbana, as cidades inteligentes. No contexto da cidades inteligentes, informação, conhecimento e inovação; desenvolvimento sustentável; globalização e governança são aspectos relevantes e que devem tomar a agenda de todos os atores sociais de forma a permitir que os intrincados problemas decorrentes do fenômeno da urbanização possam ser melhor entendidos e equacionados, para além de qualquer potencial determinismo tecnológico que a definição do tema possa sugerir. Pretende-se contribuir com as arenas multidisciplinares de discussão que vislumbrem novas possibilidades para a resolução dos intrincados problemas advindos do fenômeno da urbanização.

Palavras-chave: Cidades inteligentes; Gestão pública; Desenvolvimento sustentável; Governança pública; Inovação.

\begin{abstract}
The new global dynamic has required cities to turn to important issues surrounding their role on the global scene: increasing the competitiveness of the countries where they are located and promoting prosperity for their residents and organizations that operate there as well. Based on the literature review, this essay proposes a reflection on the imperative actions required for public managers and other social actors in order to face the challenges posed to cities so that they can stand out in the contemporary scenario in which the intense urbanization: competition for markets, permanent and growing emergence of technologies, requirements for sustainable development, effective governance and a new paradigm for urban management. In the context of smart cities, information, knowledge and innovation; sustainable development; globalization and governance are relevant aspects that should take the agenda of all social actors in order to allow the intricate problems arising from the phenomenon of urbanization are better understood and equated, in addition to any potential technological determinism the definition of the theme can suggest. This essay is intended to contribute to the multidisciplinary arenas of discussion that envisage new possibilities for solving the intricate problems arising from the phenomenon of urbanization.
\end{abstract}

\footnotetext{
${ }^{1}$ Doutor em Administração (FEI/SP). E-mail: mw@marcosweiss.com.br
} 
Keywords: Smart cities; Public Management; Sustainable Development; Public Governance; Inonovation. 


\section{INTRODUÇÃO}

A história da humanidade tem sido permeada por uma infinidade de mudanças em todas as suas dimensões e, particularmente, na forma como as pessoas se aglutinam e se organizam em torno dessas mudanças, compartilhando objetivos e princípios, costumes, espaços e também preocupações e desafios. Ao longo do tempo, as sociedades evoluíram de padrões de organização simples, como as tribos de caçadores e posteriormente as aldeias rurais, para padrões mais complexos que originaram as vilas e, delas, para as cidades. Novos padrões sociais e culturais, novas formas de produção e comércio, interações e colaborações, novas tecnologias decorrentes da inegável inventividade humana, assim como novos códigos de conduta e leis, novas formas de controle, de comando e de participação também evoluíram de forma a acompanhar as novas formas de agrupamentos de pessoas. Como organizações, as cidades, ao longo do tempo, vão se moldando para atender aos novos modelos sociais e o inverso é de igual forma verdadeiro: novos modelos sociais vão determinando o desenho da cidade, prenunciando um ciclo ininterrupto de demanda-atendimento do espaço urbano. 0 avanço da importância das cidades no contexto global, como afirmado por Sassen (1998), fortalece igualmente o surgimento e a consolidação de novas dimensões da sociedade em que o progresso das tecnologias, principalmente das tecnologias da informação e comunicação (TICs), é parte integrante e fundamental. As TICs têm se posicionado como importantes vetores para o estreitamento das relações entre as cidades ao redor mundo, entre as pessoas, entre as organizações e, principalmente, vêm encurtando as distâncias entre atores sociais, permitindo que informações de toda natureza atravessem fronteiras e estejam disponíveis praticamente em tempo real, em qualquer parte do planeta, alicerçando e promovendo novas formas de colaboração científica, tecnológica, comercial, legal e cultural (BOSCHMA, 2005; MEIER; ULFERTS; HOWARD, 2011; PALLOT et al., 2011).

Essas tecnologias têm possibilitado a criação de um mundo virtual capaz de viabilizar uma sociedade em rede em que os fenômenos sociais e econômicos acontecem instantaneamente, impulsionando a criação de mais e mais redes e determinando o surgimento de um novo desenho urbano em que a informação e o acesso a ela são seus principais fundamentos (CASTELLS, 2012). Além disso, elas têm transformado a forma como negócios são realizados, os padrões de comportamento social e começam a possibilitar que, por meio de sistemas especializados, os diversos componentes dessas tecnologias funcionem de forma integrada, permitindo o gerenciamento da dinâmica urbana e acarretando efeitos benéficos na 
vida econômica, social e cultural das cidades, além de se tornarem cada vez mais foco de pesquisa e desenvolvimento do setor de TICs (HALL et al., 2000). De fato, noção de crescimento das cidades baseada na implementação de um bom planejamento urbano, está sendo fortalecida com a ideia de transformá-las em ambientes urbanos mais inteligentes. Essas tecnologias, e particularmente a internet, estão impelindo líderes governamentais, principalmente em âmbito local, a considerar em seus planejamentos não somente o mundo físico, como também o uso das TICs para conquistar melhores resultados na economia, meio ambiente, infraestrutura, serviços e governança (HARISSON; DONNELLY, 2011; CHOURABI et al., 2012).

Nesse contexto, o tema cidades inteligentes tem se mostrado objeto de discussões e reflexões em várias esferas da sociedade e tem sido objeto de estudos em diferentes áreas do conhecimento que atribuem às TICS posição nuclear para a sua viabilização.

A literatura mostra que a adoção das TICs é a principal característica das cidades inteligentes, apresentada de forma isolada ou em combinação com outras dimensões das cidades. Em todos os casos, o bem-estar dos cidadãos e o desenvolvimento econômico e social aparecem como os mais importantes objetivos a serem alcançados e como abordagem razoável para que os complexos problemas decorrentes da intensa urbanização possam ser equacionados (HALL et al., 2000; ODENDAAL, 2003; KOMNINOS, 2006; GIFFINGER et al., 2007; EGER, 2009; KANTER; LITOW, 2009; CHEN, 2010; GIFFINGER; HAINDLMAIER, 2010; HARRISON et al., 2010; TOPPETA, 2010; WASHBURN et al., 2010; CANTON, 2011; CARAGLIU; DEL BO; NIJKAMP, 2011; DUTTA et al., 2011; HERNÁNDEZ-MUÑOZ et al., 2011; NAM; PARDO, 2011a; SCHAFFERS et al., 2011; THITE, 2011; THUZAR, 2011; VELOSA et al., 2011; BAKICl; ALMIRALL; WAREHAM, 2012; BARRIONUEVO et al., 2012; CHOURABI et al., 2012; CRETU, 2012; GUAN, 2012; KOURTIT; NIJKAMP; ARRIBAS, 2012; KOURTIT; NIJKAMP, 2012; LAZAROIU; ROSCIA, 2012; LOMBARDI et al., 2011; POL et al., 2012; LEE; PHAAL; LEE, 2013; ZYGIARIS, 2013; MARSALLLACUNA et al., 2015). Ademais, a instituição de cidades inteligentes exige abordagens pragmáticas e que considerem de forma plena como as cidades desenvolvem suas responsabilidades de atenção aos atores no dia-a-dia e como a interação ator-poder público se dá efetivamente. Nesse sentido, a inteligência da cidade deve estar fortemente associada às suas habilidades de transformar necessidades e obrigações em sistemas de informação robustos, integrados, escaláveis e resilientes utilizando, para tanto, os constantes avanços promovidos pela indústria de TICs. Mais do que isso, é fundamental que gestores públicos em nível local e sociedade estejam atentos e dispostos a entender, discutir e agir com relação aos 
principais aspectos motivadores que devem ser perseguidos concomitantemente com a adoção de tecnologias para a gestão das cidades.

Nesse sentido, e de forma colaborativa com autores e estudiosos citados nesse trabalho, defino a cidade inteligente como aquela que realiza a implementação de tecnologias da informação e comunicação - TICS - de forma a transformar positivamente os padrões de organização, aprendizagem, gerenciamento da infraestrutura e prestação de serviços públicos, promovendo práticas de gestão urbana mais eficientes em benefício dos atores sociais, resguardadas suas vocações históricas e características culturais.

Colocadas essas reflexões iniciais, esse trabalho tem por objetivo refletir sobre questões que extrapolam o determinismo tecnológico ou a simples adoção de tecnologias para a gestão das cidades, conclamando os atores sociais e principalmente gestores públicos em nível local à reflexão e a ação para a adoção e a prática de paradigmas de gestão empresarial, capazes de implementar no âmbito da gestão pública progressivas eficácia e eficiência; para a necessidade premente de privilegiamento do trânsito de informações e conhecimentos, impulsionando o espírito inovador dos atores; para a criticidade que o desenvolvimento sustentável e a sustentabilidade assumem nesse início de século; para as questões que envolvem o fenômeno da globalização em todos os seus benefícios e controvérsias e finalmente, mas não menos importante, para a governança urbana, em que estejam inequivocamente presentes a transparência, a prestação de contas, a responsabilidade objetiva, igualdade e inclusividade.

\section{O CONTEXTO URBANO: O MUNDO EM QUE VIVEMOS}

Há um século, havia menos de vinte cidades ao redor do mundo com população acima de 1 milhão de habitantes. Em 2010, esse número avançou para 436 e as projeções indicavam mais de 500 cidades com população acima de 1 milhão de habitantes até o final de 2015, segundo o estudo World Urbanization Prospects: the 2014 revision (ONU, 2014), publicado pela Organização das Nações Unidas (ONU). O mesmo estudo mostrou que o fenômeno do crescimento populacional, particularmente nas áreas urbanas, não guarda similaridade a qualquer outro fenômeno social já descrito. Ao anunciar esse estudo, John Wilmoth, Diretor do United Nations Department of Economic and Social Affairs - Population Division (UN-DESA), afirmou: "Managing urban areas has become one of the most important development challenges of the 21st century. Our success or failure in building sustainable cities will be a major factor in the success of the post-2015 UN development agenda" (ONU, 2014). 
Atualmente, em todo mundo, mais pessoas vivem em áreas urbanas do que em áreas rurais e o ano de 2007 foi o marco histórico que determinou a transição do rural para o urbano e, desde então, a população mundial tem sido predominantemente urbana. Estudos mostram que mais da metade da população mundial vive presentemente em áreas urbanas e a tendência é que esse fenômeno persista pelos próximos trinta e cinco anos. Em outras palavras, a população total projetada para 2050 deverá saltar dos atuais 7,3 para aproximadamente 9,5 bilhões de pessoas, sendo que a população urbana terá saltado de 3,9 para algo perto de 6,3 bilhões. Isso significa que, enquanto a população mundial terá crescido de 2015 até 2050 à ordem $30,4 \%$, a população urbana no mesmo período terá crescido à ordem de $60,2 \%$, como apresentado na llustração 1.

Ilustração 1 - Projeção do crescimento populacional global.

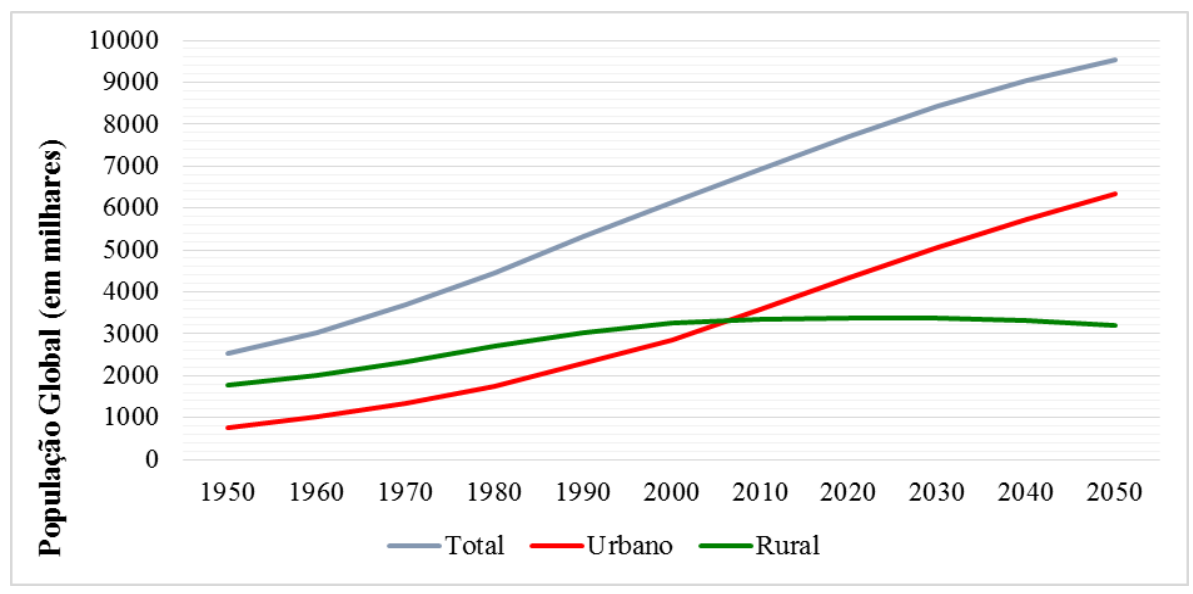

Fonte: Autor "adaptado de" ONU, 2014.

Ásia, África e o Continente Americano vivem crescimentos populacional, enquanto a Europa apresenta crescimento muito menos intenso e, em muitos casos, diminuição da população. África e Ásia projetam-se como as regiões de crescimento mais acentuado e se configuram como as regiões de maior contribuição para os níveis projetados de concentração populacional urbana para 2050. O crescimento da população urbana, entretanto, não obedece ao mesmo padrão de crescimento da população global. Se tomadas as estimativas de crescimento para 2015 e para 2050 comparativamente, se observará que a população total deverá crescer menos do que a população urbana ou apresentará crescimento total negativo, como no caso da Europa. Tomadas as perspectivas da ONU para a expansão dos ambientes urbanos, é possível observar, como apresentado na llustração 2, que os países chamados desenvolvidos, acompanhados dos países da América Latina e Caribe, já têm a maioria de suas 
populações vivendo nesses ambientes e, embora apresentem crescimentos menos acentuados, elas permanecerão crescendo em termos proporcionais.

\section{Ilustração 2 - Crescimento da população urbana em relação à população total.}

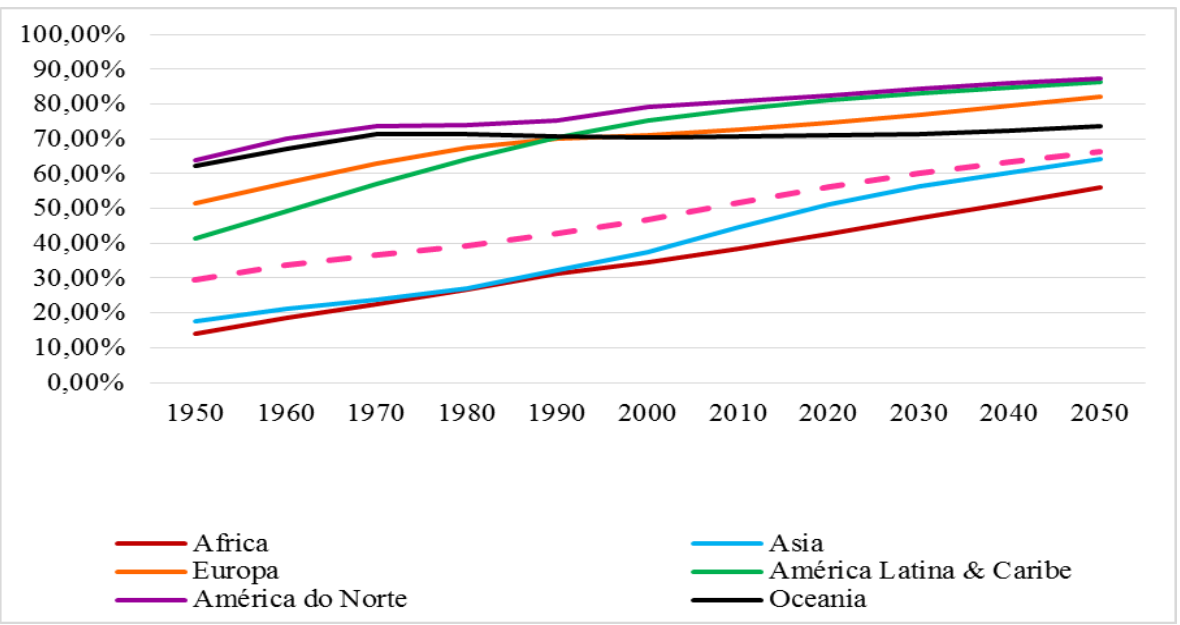

Fonte: Autor "adaptado de" ONU, 2014.

Em todas as regiões do planeta, a população urbana se manterá crescente, ao ponto de superar, em média, a taxa de crescimento de $60 \%$ contra $30 \%$ de crescimento populacional total médio, como se pode observar na Erro! Fonte de referência não encontrada..

Ilustração 3 - Quadro comparativo de crescimento populacional total e urbano: 2015-2050.

\begin{tabular}{|c|c|c|c|c|c|c|}
\hline \multirow{2}{*}{ Região } & \multicolumn{2}{|c|}{$\begin{array}{l}\text { População Total } \\
\text { Estimada }\end{array}$} & \multicolumn{2}{|c|}{ População Urbana Estimada } & $\mathrm{Cr}$ & $\begin{array}{l}\text { Crescimento Relativo da } \\
\text { População 2015-2050 }\end{array}$ \\
\hline & 2015 & 2050 & 2015 & 2050 & $\begin{array}{l}\text { População } \\
\text { Total }\end{array}$ & População Urbana \\
\hline África & 1.166 .239 & 2.393 .175 & 471.602 & 1.338 .566 & $105,2 \%$ & $183,8 \%$ \\
\hline Ásia & 4.384 .844 & 5.164 .061 & 2.113 .137 & 3.313 .424 & $17,8 \%$ & $56,8 \%$ \\
\hline Europa & 743.123 & 709.067 & 547.066 & 581.113 & $-4,6 \%$ & $6,2 \%$ \\
\hline $\begin{array}{l}\text { América } \\
\text { Latina \& } \\
\text { Caribe }\end{array}$ & 630.089 & 781.566 & 502.793 & 673.631 & $24,0 \%$ & $34,0 \%$ \\
\hline $\begin{array}{l}\text { América do } \\
\text { Norte }\end{array}$ & 361.128 & 446.201 & 294.834 & 390.070 & $23,6 \%$ & $32,3 \%$ \\
\hline Oceania & 39.359 & 56.874 & 27.853 & 41.807 & $44,5 \%$ & $50,1 \%$ \\
\hline
\end{tabular}

Esse fenômeno de intensa urbanização também se observa refletido no Brasil, configurando-se também como um evento social irreversível visto os consideráveis recursos investidos ao longo do tempo não podem ser simplesmente abandonados. O censo 
demográfico de 2010, divulgado pelo Instituto Brasileiro de Geografia e Estatística (IBGE) em 2012, mostra que a população brasileira já havia ultrapassado à época o patamar de 190 milhões de habitantes e que, aproximadamente, $80 \%$ deles já viviam em ambientes urbanos. Segundo o mesmo Instituto, a população rural em 2010 é, em termos absolutos, a mesma de 1940, embora a população do país tenha quase que se multiplicado por cinco, considerando o mesmo período de comparação (IBGE, 2012), conforme se pode observar na llustração 3.

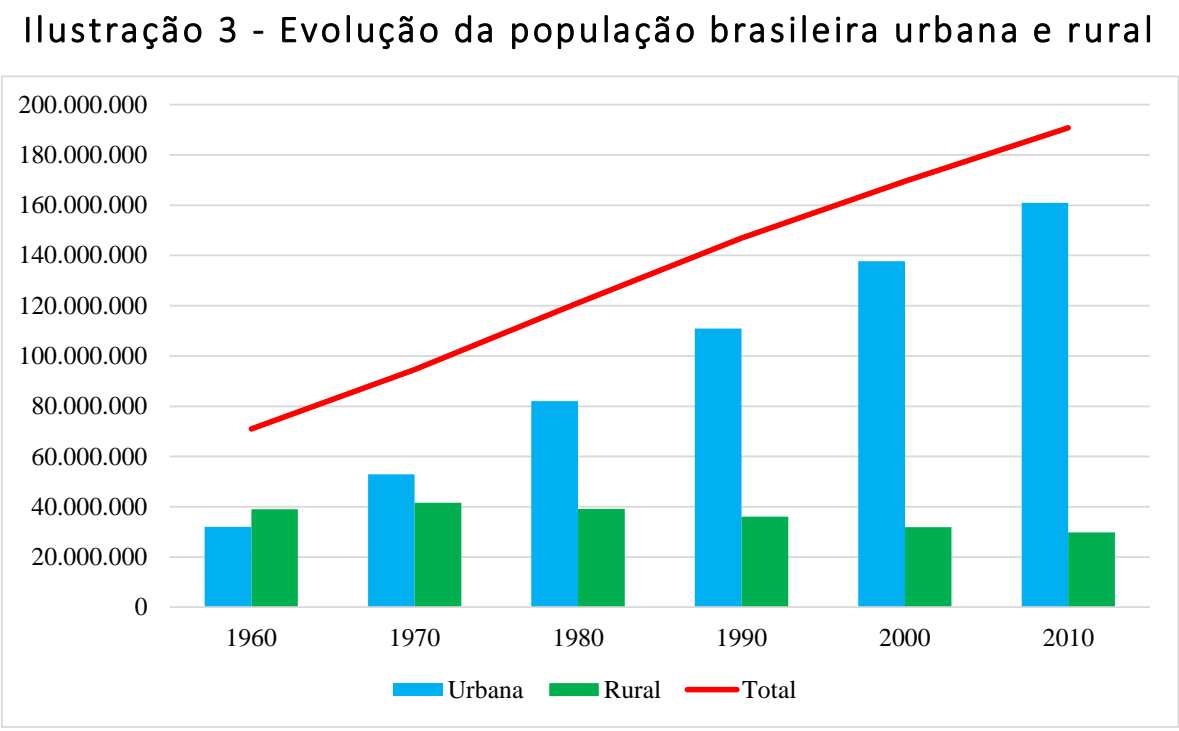

Fonte: IBGE, 2012.

Os dados mostram que as próximas décadas serão permeadas por importantes mudanças na forma como os espaços deverão ser ocupados, assim como na forma como as cidades deverão tratar a questão da concentração de pessoas em seus domínios. Embora a África e a Ásia representem, tanto em termos absolutos quanto em termos relativos, as principais áreas de crescimento, o fenômeno se repete em todo o globo. Independentemente das razões que justifiquem tal crescimento populacional - aumento nas taxas de natalidade, aumento da expectativa de vida nas cidades, migração das populações rurais para os ambientes urbanos ou mesmo o crescimento populacional associado à mortalidade nas áreas rurais - o fato é que as cidades enfrentarão, inevitavelmente, importantes desafios. Como o fenômeno da urbanização se apresenta como praticamente irreversível, o enfrentamento aos desafios para se alcançar a prosperidade e o desenvolvimento sustentável vai se consolidando como a principal e mais importante agenda para as lideranças governamentais em todas as esferas, mas principalmente para os líderes em nível municipal.

Como observado, segundo a ONU mais de 2 bilhões de pessoas serão somadas à 
população urbana atual e isso incrementará as demandas por alimentos, água, saneamento básico, energia, educação em todos os níveis, saúde, oportunidades de trabalho, transporte, segurança, moradia, lazer e cultura, para além das demandas por serviços sociais e de atenção às pessoas e organizações e preservação dos recursos naturais. Se tais demandas podem não ser de maior relevância para as regiões de menor crescimento ou de vida urbana mais desenvolvida, como na Europa ou na América do Norte, elas são de grande relevância para outras regiões menos desenvolvidas, como no caso da África, da Ásia e para a América Latina e Caribe (ONU, 2014).

O relatório State of the World's Cities Report 2012/2013: Prosperity of Cities, publicado pela UN-Habitat, programa das Nações Unidas para os Assentamentos Humanos, ao posicionar as cidades como solução para as crises globais, declara:

As cidades são os lugares onde os seres humanos encontram e satisfazem suas necessidades básicas e bens públicos essenciais. Onde vários produtos podem ser encontrados em suficiência e utilidade apreciadas. As cidades são também os lugares onde ambições, aspirações e outros aspectos imateriais da vida são realizados, proporcionando satisfação e felicidade, aumentando as perspectivas de bem-estar individual e coletivo. No entanto, quando a prosperidade não se faz sentir ou é restrita a alguns grupos, quando só é sentida em algumas partes da cidade, quando é usada para atender a interesses específicos, ou quando é uma justificativa para ganhos financeiros por poucos em detrimento da maioria, a cidade torna-se o locus onde o direito à prosperidade compartilhada é reivindicado e objeto de luta (UN-HABITAT, 2012, p. 10, tradução nossa).

De fato, enquanto as cidades crescem em quantidade e em população, elas se posicionam centralmente no cenário global: do ponto de vista econômico, elas se conforma como vetores para a integração global dos fluxos de informações, conhecimentos e negócios, avançando em direção à uma sociedade baseada em serviços, gerando valor e riquezas por meio de ecossistemas técnico-científicos e arquiteturas empresarias propícias à inovação; da perspectiva social, as cidades se consolidam como núcleos de agregação e paradigma de socialização da humanidade, onde as pessoas realizam suas expectativas de inclusão e qualidade de vida; do ponto de vista político, se apresentam como espaços críticos para a gestão pública, impondo desafios e dilemas relativamente à capacidade de resposta do poder público quanto a um planejamento urbano que estimule a inovação e a competitividade, interferindo com maior influência e responsabilidade no realinhamento do poder em favor dos atores sociais, em quaisquer esferas em que se encontrem. Nesse sentido, a forma como as cidades enfrentam seus desafios substantivos e inter-relacionados torna claro que as presentes 
práticas de provimento e gerenciamento das infraestruturas e serviços públicos exigem constante busca de transformação no sentido de atender mais e melhor às necessidades e expectativas dos atores.

\section{UM CHAMAMENTO À AÇÃO PARA A ADOÇÃO E PARA A PRÁTICA DE PARADIGMAS DE GESTÃO EMPRESARIAL}

Como qualquer organização, as cidades serão cada vez mais pressionadas a produzir resultados que sejam reconhecidos como capazes de prolongar sua perenidade e garantir um ciclo de vida virtuoso em benefício de todos os stakeholders: cidadãos, visitantes, empresas, governos e quaisquer outros atores que nelas atuam ou delas dependam. Assim, o desenvolvimento e a exploração das capacidades dinâmicas das cidades se configuram como possibilidade para que elas possam construir, integrar e reconfigurar suas competências internas e externas, de forma a se adaptar rapidamente às mudanças que se avizinham (TEECE; PISANO; SHUEN, 1997).

O cenário que se presencia mostra que as cidades devem se valer de sua posição na cena global para que se tornem mais inteligentes e, com o auxílio de novas tecnologias, principalmente as tecnologias da informação e comunicação (TICs), transformem as formas e os padrões de geração e uso dos recursos urbanos, prolongando seus ciclos de vida em favor de todos os atores e incrementando suas competências de atrair e manter novos atores.

As cidades dependem de seus sistemas de negócios para prosperar e, como estão cada dia mais presentes no contexto global, a falta de eficiência na tramitação da licença de operação de uma empresa, por exemplo, pode significar a perda dessa empresa para outra cidade mais eficiente. Sistemas administrativos menos eficientes podem levar ao insucesso, e a burocracia, baseada em infinitos formulários e intervenções manuais de agentes públicos, pode representar significativos custos adicionais à gestão pública e aos cidadãos; a urbanização e a globalização criam mais passageiros e mais trânsito de mercadorias em todos os modais logísticos existentes e os congestionamentos do tráfego nas cidades, por incapacidade de o poder público realizar e executar planos de mobilidade adequados às demandas dos atores, pode resultar, além de perdas em receitas, em redução de qualidade de vida e de competitividade no mundo dos negócios; a eficiência no fornecimento de água e energia são também imprescindíveis para a prosperidade das cidades visto que perdas por incapacidade de pronta reação a desastres, vazamentos e mau uso, assim como pouca racionalidade na geração 
e uso da energia, são limitadores para seu desenvolvimento; as restrições na qualidade da educação, saúde e segurança pública influenciam negativamente a qualidade de vida das pessoas, representando riscos para todos, mas particularmente para as empresas, riscos adicionais no que diz respeito à disponibilidade e qualidade da mão de obra existente; acrescente-se a esses aspectos o fato de que os últimos 20 anos viram uma revolução na forma como as pessoas se comunicam, se informam e compartilham informações, particularmente por conta do advento da rede mundial de computadores - a internet - onde organizações de qualquer natureza que não encontrem as condições de infraestrutura de comunicações adequadas para suportar suas operações podem vislumbrar outras opções de localização geográfica onde suas demandas sejam mais bem atendidas.

A despeito desses substantivos desafios que as cidades enfrentam, elas têm uma gama de serviços que devem entregar aos seus atores, particularmente aos seus cidadãos. Muitas se esforçam para fornecer um ambiente de vida saudável, agradável e seguro para os seus residentes. Também se esforçam para atrair negócios, ajudá-los a prosperar em uma economia global competitiva, bem como proporcionar infraestruturas eficientes e eficazes, de forma sustentável. Para atingir seus objetivos, devem atentar para os sistemas nos quais estão baseando suas aspirações de forma a torná-los mais inteligentes. Ademais, a adoção e implementação de práticas de gestão empresarial para a gestão das cidades, uma vez reconhecidas e exploradas suas competências centrais, podem transformar e projetar essas cidades, fazendo com que agentes públicos e iniciativa privada colaborem entre si, dando sustentação a projetos de renovação urbana com vistas à dinâmica econômica, com equilíbrio entre continuidade e mudança (SÁNCHEZ, 2010).

Graças aos avanços das TICs e à intensificação de sua utilização em diferentes áreas da dinâmica urbana, as cidades estão cada dia mais interconectadas e instrumentalizadas, proporcionando significativos benefícios aos atores. Entretanto, o sucesso na aplicação dessas tecnologias exige que dois vetores sejam considerados. O primeiro diz respeito ao gerenciamento dos recursos a partir da perspectiva do desenvolvimento sustentável, de forma a transformar as cidades em lugares que sejam atrativos para cidadãos e organizações. Isso significa implementar processos e ferramentas inovadores para o gerenciamento das infraestruturas e serviços públicos, permitindo ao poder público maior capacidade de integração de ativos, eficiência na prestação de serviços, predição e custos aceitáveis (ALHADER; RODZI, 2009; TOPPETA, 2010; WASHBURN et al., 2010; WOLFRAM, 2012). O segundo diz respeito ao estabelecimento de um ambiente atrativo do ponto de vista socioeconômico, 
onde cidadãos e organizações possam interagir satisfatoriamente, sem restrições que mereçam intervenções drásticas. Isso significa imprimir eficiência e reformular a organização da dinâmica urbana, tendo as TICs como viabilizadoras de uma arquitetura que possa implementar maior inteligência nas cidades (STORPER, 1997; EGER, 2009; TOPPETA, 2010; WASHBURN et al., 2010; NAM; PARDO, 2011a; BATAGAN, 2011; DOGDSON; GANN, 2011; DUTTA et al., 2011; CADENA; DOBBS; REMES, 2012; WOLFRAM, 2012).

Nesse contexto e sob as perspectivas da potencial conturbação da dinâmica urbana e do permanente avanço das TICs, o conceito de cidade inteligente surge e evolui como uma forma de utilizar intensivamente as inovações em TICs como viabilizadoras da competitividade econômica, da sustentabilidade ambiental e da qualidade de vida geral, incrementando as capacidades de aprendizagem, inovação e desenvolvimento tecnológico aplicados nos processos próprios do gerenciamento urbano e proporcionando melhores condições de vida para as pessoas e de operação para as organizações. Novas tecnologias ubíquas fornecem maior capacidade e desempenho para que os subsistemas urbanos possam interagir de forma plena, propiciando efetividade na gestão urbana. Elas permitem que os gestores municipais sejam capazes de se antecipar a questões críticas, como gestão da água, intervenção em tempo real no sistema viário, disponibilização de conteúdos educacionais de forma digital, aprimoramento do atendimento do sistema público de saúde ou ainda redução do deslocamento dos cidadãos e outros atores aos postos de atendimento do poder público (KANTER; LITOW, 2009; GIFFINGER; HAINDLMAIER, 2010; TOPPETA, 2010; WASHBURN et al., 2010; ALLWINKLE; CRUICKSHANK, 2011; CHOURABI et al., 2012; DUTTA et al., 2010; HARRISSON; DONNELLY, 2011; HERNÁNDEZMUÑOZ et al., 2011; KOMNINOS, 2011; NAM; PARDO, 2011a; NAM; PARDO, 2011b; SCHAFFERS et al., 2011; CADENA; DOBBS; REMES, 2012). Por essas e outras razões, organizações governamentais e não governamentais, firmas globais de consultoria por intermédio de seus departamentos de pesquisa e desenvolvimento, empresas líderes da indústria de TICs e universidades em todo o mundo têm empenhado recursos humanos, técnicos e financeiros para o melhor entendimento dos problemas que afetam a dinâmica urbana e para a busca de soluções inovadoras viáveis, assim como para determinar as formas e conteúdos característicos de uma cidade inteligente.

Não obstante a importância e criticidade que as TICs assumem no cenário das cidades inteligentes, não se postula que essas tecnologias por si só sejam suficientes o bastante para resolver todos os problemas da sociedade, de forma autônoma e sem direta relação com essa mesma sociedade. Ao contrário, no contexto das cidades inteligentes, essas tecnologias devem 
estar disponibilizadas em quantidade e qualidade suficientes para que a sociedade, em todos os seus segmentos, possa delas se valer para realizar suas necessidades e expectativas. O determinismo tecnológico não deve ser o direcionador para o desenvolvimento e para a implementação das cidades inteligentes. Ao contrário, postula-se que os valores, a cultura, a história e as próprias necessidades da sociedade sejam os estimuladores e razões suficientes para que novas tecnologias possam ser desenvolvidas e sustentadas ao longo do tempo não se afirmando, portanto, que os avanços e os desenvolvimentos de novas tecnologias determinam e influenciam a dinâmica social ao ponto de serem consideradas causa e não efeito (FEENBERG, 2010). Ademais, a nova dinâmica global tem sido caracterizada como uma dinâmica fundamentada na informação e no conhecimento, graças à capacidade de interação, integração e colaboração entre os diferentes atores econômicos especializados, que vislumbram novas formas de construção e manutenção de uma nova ordem urbana, capaz de consolidar os caminhos rumo ao desenvolvimento sustentável (WOLFE; BRAMWELL, 2008).

\section{UM CHAMAMENTO À AÇÃO PARA O TRÂNSITO DE INFORMAÇÕES, CONHECIMENTOS E FOMENTO À INOVAÇÃO}

Ao se posicionarem como fontes e canais para o trânsito de informação e geração de conhecimento, as cidades vão se consolidando como espaços singulares para o desenvolvimento econômico sustentável, promovendo transformações urbanas que tendem a beneficiar não somente a si mesmas, mas também a outras que estão em proximidade geográfica, comercial, institucional ou mesmo virtual. O desafio que se interpõe para que esse fluxo de informações e conhecimentos aconteça está diretamente relacionado ao estímulo permanente para que novas concepções de produtos e serviços aconteçam e que o aprendizado, derivado das experiências, seja plenamente integrado aos aspectos culturais e sociais onde ocorrem. Essa permanente interação informação-conhecimento se configura como uma possibilidade razoável para que muitos dos novos problemas advindos da urbanização encontrem soluções adequadas e possam, de certa forma, ser compartilhadas por outras cidades. Conhecimento e informação estão presentes em todas as cidades, embora as cidades maiores e mais desenvolvidas social e economicamente possam ser tidas como mais propícias à intensificação de conhecimentos e especializações, quer pelas possibilidades de atração de investimentos e mão-de-obra altamente qualificada, quer por suas características e vocações sociais e culturais (BRENNER, 1998; DURANTON; PUGA, 1999; JOHNSON, 2008; EVANS, 2009; 
QUIGLEY, 2009). As cidades desempenham um papel estratégico, tanto local quanto globalmente, para a criação dos fundamentos para o conhecimento e para a inovação nos âmbitos institucional, social e econômico, possibilitando o surgimento de soluções para os mais importantes problemas sociais contemporâneos (KULKKI, 2014).

Nesse ponto, o creative milieu proposto por Landry (2008), vai se configurando como um instrumento inequívoco para a identificação, encorajamento, atração e manutenção de talentos capazes de mobilizar e atrair outros tantos talentos e organizações criativas capazes de produzir novas ideias e invenções. Organizadas ao redor de sistemas produtivos e científicos, marcados pela colaboração e interação entre os atores, que oferecem um contexto importante para a geração de informações e conhecimentos de alto nível, resultando experimentações e práticas fundamentais para os processos alavancadores de crescimento e desenvolvimento. Em um ciclo virtuoso, propiciam o surgimento de novas formas de gestão e liderança, de educação, de atividade econômica e de inserção no contexto global, com flexibilidade, adaptabilidade e resiliência (HALL, 2000; SCOTT, 2006; LANDRY, 2008; EVANS, 2009; DOGDON; GANN, 2011).

Glaeser e Saiz (2003) afirmam que as cidades com capital humano mais qualificado tendem a ser mais inovadoras e capazes de reagir a contingências da economia de forma mais rápida e alternar técnicas em métodos produtivos e de gestão. Sobre isso, Winden (2008) argumenta que algumas cidades crescem mais fortemente do que outras justamente por que são capazes de funcionar como imãs para a atração de talentos e investimentos ao passo que outras cidades, menores ou sem alguma especialização perdem o que têm em favor das primeiras. O capital humano torna-se, então, a chave principal para que as capacidades das cidades possam ser apropriadamente exploradas, garantindo um processo constante de reinvenção, determinando inclusive as taxas de crescimento e desenvolvimento. O mesmo autor argumenta ainda que "as cidades podem ser consideradas como os pontos focais da economia do conhecimento, porque é nas cidades que o conhecimento é produzido, transformado, trocado e comercializado" (WINDEN, 2008, p. 199, tradução nossa).

Ao criar espaços adequados - físicos ou virtuais - para a troca de informações e a para a produção de conhecimentos que possam estar disponíveis para que todos os atores deles se apropriem, as cidades avançam na criação de novas ideias e inovações, agindo como interface entre todos esses atores. A produção de conhecimento e de inovações não está, entretanto, limitada a áreas específicas, como parques científicos ou a instalações universitárias. O relacionamento sólido entre academia-empresa-governo pode contribuir para a criação de novos nós nas redes de inovação urbana, capazes de estimular, gerar, promover e catalisar as 
inovações nas cidades, particularmente aquelas que busquem enfrentar e solucionar as situações potencialmente adversas trazidas pela intensa urbanização. Ao associar as pessoas, processos, tecnologias e infraestruturas físicas, para além da destinação de recursos financeiros adequados e adequadamente gerenciados, as cidades podem promover novas relações entre polos de pesquisas e empresas, estabelecer lugares de produção apropriados pelos agentes promotores de conhecimento e proporcionar novos canais e fluxos para a produção de novos conhecimentos.

Historicamente, as cidades têm se posicionado como polos onde tecnologias, de toda natureza, são desenvolvidas, assim como onde se encontram os maiores problemas e desafios para as populações. O conhecimento codificado atravessa fronteiras, graças às flexibilizações nos atos regulatórios que normatizam as atividades entre mercados e aos avanços das tecnologias da informação e comunicação, propiciando maior dinamismo na atividade econômica e intensificação da criação e universalização de mais conhecimento, a custos praticamente iguais a zero (BATHELT; MALMBERG; MASKELL, 2004). As cidades que contam e desenvolvem suas capacidades de construção e intensificação de conhecimento e sistemas de inovação robustos, estabelecendo uma relação simbiótica entre a dinâmica urbana e a inovação, estão mais propensas a obter sucesso, mesmo que em condições de competição intensa frente a outras cidades mais desenvolvidas: a inovação e o aprendizado são os principais fatores que encorajam o desenvolvimento de novos processos e produtos, estimulando o empreendedorismo, principalmente em áreas intensivas em tecnologias avançadas, transformando a inovação e o aprendizado em duas facetas importantes para o posicionamento das cidades no contexto global. (BEGG, 1999; WINDEN, 2008; WOLFE; BRAMWELL, 2008; DOGDSON; GANN, 2011).

Nesse sentido,

“(...) é chegado o tempo de mostrar como as cidades inovadoras e a inovação nas cidades podem fazer frente aos desafios da sustentabilidade, à criação e distribuição de riquezas, aos investimentos necessários em infraestrutura, reduzindo a pobreza e funcionando de forma eficaz e eficiente em benefícios de todos" (MARCEAU, 2008, p. 145, tradução nossa).

O cenário do crescimento urbano faz com que as cidades busquem alternativas e coloque esforços no fomento à criatividade e na inovação, de forma a que sejam lançadas as bases para uma nova ordem urbana (BOYKO et al., 2006; SCOTT, 2006; JOHNSON, 2008; BARNES, 2010). Nessa altura, é relevante afirmar que a inovação não está restrita às empresas, assim como ciência e tecnologia não estão circunscritas aos ambientes acadêmicos. Entretanto, 
esses fenômenos sociais determinantes do progresso humano, acontecem em ambientes urbanos, sem qualquer privilégio deste em relação a aquele, exceto pelas condições que são criadas e oferecidas para aconteçam (HALL, 2000; SCOTT, 2006; JOHNSON, 2008; AHMAD; COLIN; AHMED, 2012; GAWEL, 2012). Ao combinar apropriadamente os recursos humanos, técnicos e financeiros, aliados às competências de gestão e ao estímulo governamental, as perspectivas de desenvolvimento de novas capacidades científicas e tecnológicas se fortalecem, propiciando o surgimento de soluções para que uma nova ordem urbana seja estabelecida. Essa nova ordem, baseada nas características eminentemente interativas da inovação e do aprendizado, determinam os fundamentos para o desenvolvimento econômico, capaz de criar vantagens nos custos de transações e motivar mais inovações e aprendizados (FELDMAN; AUDRETSCH, 1999; CORIAT; DOSI, 2002; WOLFE; BRAMWELL, 2008; DOGDSON; GANN, 2011), para a manutenção e renovação do meio ambiente e, principalmente, para a prosperidade social (DIRKS; GURDGIEV; KEELING, 2010; EKINS, 2010; MACHIBA, 2010; RASOOLIMANESH; BADARULZAMAN; JAAFAR, 2011; AHMAD; COLIN; AHMED, 2012). Uma vez combinados os recursos e estabelecidos os objetivos de desenvolvimento sustentável, os diferentes atores urbanos encontram as bases para que possam promover e se beneficiar do compartilhamento e integração de informações e conhecimentos e vice-versa, pavimentando os caminhos para a implementação de sistemas urbanos eficientes, competitivos, inteligentes e desejáveis, capazes inclusive de motivar o estabelecimento de similaridades para além de suas fronteiras jurisdicionais (EGER, 2009; BATAGAN, 2011; SEELIGER; TUROK, 2013).

Então, respeitadas as diversidades de características históricas, culturais e sociais das cidades, o ímpeto para a inovação e para o aprendizado, próprio dos ambientes urbanos, estabelece acessos a vários tipos de redes de conhecimento (BEGG, 1999), atraindo investimentos na implantação de empresas e, em muitas situações, no estabelecimento de centros de formação profissional e universidades. Seja por sua especialização na área industrial, em toda sua diversidade, ou em setores mais específicos, como na área de serviços intensivos em conhecimento (WOLFE; BRAMWELL, 2008), ao focalizarem o fomento à ciência, tecnologia e inovação, as cidades podem prover uma importante variedade de soluções tecnológicas aplicáveis ao contexto urbano, desde as mais simples ou renovadas até as mais complexas, para além de novas abordagens para o planejamento e gestão de toda sorte organizações, incluindo as próprias cidades. Em outras palavras, ciência, tecnologia e inovação são os principais direcionadores para o crescimento econômico e para a prosperidade social. Ao desenvolver uma cultura voltada para esses temas, por meio da promoção do espírito empreendedor, da 
identificação e formação de talentos, da implementação de políticas públicas e do estímulo ao estabelecimento de indústrias de alta tecnologia, os líderes municipais podem adquirir vantagem competitiva com a criação, difusão e proteção de propriedade intelectual e com a disponibilização de produtos e de serviços de alto valor. Isso requer sólidas conexões com as comunidades de ciência e tecnologia, capazes de criar um ambiente colaborativo para a realização de pesquisas e sua posterior exploração e, com isso, a geração e exploração de mais pesquisas, quer pelo setor público, quer pela iniciativa privada, tendo como vetor a busca de respostas às demandas econômicas, ambientais e sociais da sociedade. Essas conexões, muitas vezes representadas por parques de ciência e tecnologia em que estão presentes o governo, a iniciativa privada e a academia, são motores de grande importância para a criação de uma economia baseada em conhecimento e para o desenvolvimento tecnológico orientado para o mercado.

No âmbito do setor público, a despeito de suas restrições institucionais e políticas e aversão a riscos, experimentações e incertezas, para além de suas obrigações de prestação de contas à sociedade, novas formas de estímulo à pesquisa e desenvolvimento podem ser promovidas, quer por meio de projetos específicos e de interesse da cidade quer por meio de parcerias público-privadas ou ainda por meio de financiamentos privados (CATS-BARIL; THOMPSON, 1995; DAWES et al., 2004; HARTLEY, 2005; BARNES, 2010; POTTS; KASTELLE, 2010; DUTTA et al., 2011; HAMMER et al., 2011; NAM; PARDO, 2011b). Dessa forma, o espírito inovador dos líderes municipais, para além de promover as inovações na infraestrutura, nos serviços públicos e nos processos próprios da administração pública, pode estimular as transformações e o desenvolvimento da dinâmica econômica, ambiental e social, possibilitando a criação de novos conhecimentos que podem ser compartilhados e utilizados, no melhor interesse de todos (BOYKO et al., 2006; JOHNSON, 2008; YOON; TELLO, 2009; BARBIERI et al., 2010; BATAGAN, 2011; HAMMER et al., 2011; AHMAD; COLIN; AHMED, 2012). Entretanto, a criação de uma cultura de ciência, tecnologia e inovação não é garantia para que a cidade direcione suas capacidades para o desenvolvimento sustentável. De outra forma, os líderes municipais devem garantir estratégias que reconheçam que o desenvolvimento sustentável é o principal motivador para que tais iniciativas tenham força e vigor no longo prazo (JOHNSON, 2008; MACHIBA, 2010; ELKINGTON, 2012).

Embora os desafios interpostos pela concentração de pessoas em ambientes urbanos, as possibilidades de colaboração entre governos, iniciativa privada e academia se tornam críticas para que o compartilhamento de conhecimentos, capaz de produzir soluções inovadoras 
que visem o estabelecimento de estratégias para o desenvolvimento econômico e a geração de oportunidades de prosperidade para além dos limites institucionais e geográficos (ETZKOWITZ, 2002; LEYDESDORFF; DEAKIN, 2011; LOMBARDI et al., 2011). Entender e convergir tais perspectivas em busca de soluções significa intensificar os esforços em inovação. Inovação que possa trazer novas práticas e aplicações para coisas nem tão novas, determinando a forma como as cidades e a sociedade conviverão no futuro próximo.

\section{UM CHAMAMENTO À AÇÃO PARA O DESENVOLVIMENTO SUSTENTÁVEL E PARA A SUSTENTABILIDADE}

As tendências demográficas globais e suas implicações são cada vez mais fonte de preocupação com a doutrina e os princípios de sustentabilidade e com as exigências de controle e publicidade. Os desafios globais com relação às questões ambientais e sociais se materializam e se revestem de urgência nas cidades, particularmente devido à intensificação da urbanização e às exigências de projeção que elas têm para a inserção no cenário econômico global. Nesse sentido, as cidades têm se configurado como espaços estratégicos de confrontação entre as forças da produção de bens e serviços, na maioria das vezes destrutivas para o meio ambiente, e as forças que buscam a implementação de novas e equilibradas formas de produção e que tenham maior preocupação com as questões ambientais e sociais. No atual cenário de crescimento populacional e de intensa concentração de pessoas nos ambientes urbanos, tomar a sustentabilidade como objetivo é de fundamental importância. A interação permanente entre governos, iniciativa privada, academia, organizações não-governamentais e cidadãos deve permitir que sejam identificadas e implementadas alternativas que permitam que os objetivos de desenvolvimento sustentável sejam alcançados. Pensar o tecido urbano não somente como lugar para a geração de vantagens econômicas, mas também como lugar propício para a criação de alternativas de preservação ambiental e desenvolvimento social é o desafio a ser enfrentado pelos líderes sociais no curto prazo (BOYKO et al., 2006; YOON; TELLO, 2009; BATAGAN, 2011; HAMMER et al., 2011; AHMAD; COLIN; AHMED, 2012).

Com direta afetação ao âmbito local, os compromissos assumidos por Chefes de Estado vislumbram a criação de ambientes urbanos capazes de propiciar condições adequadas de vida para as populações:

Comprometemo-nos a promover uma estratégia integrada para o planejamento e construção de cidades e assentamentos urbanos sustentáveis, nomeadamente mediante o apoio das autoridades locais, 
de forma a aumentar a sensibilização do público e a participação dos residentes urbanos, incluindo os pobres, na tomada de decisões. Também nos comprometemos a promover políticas de desenvolvimento sustentável que suportem a habitação e serviços sociais inclusivos; um ambiente de vida seguro e saudável para todos, especialmente para as crianças, jovens, mulheres, idosos e deficientes; energia e transporte viáveis e com preços acessíveis; promoção, proteção e restauração de espaços verdes seguros nas cidades; água potável e limpa e saneamento; qualidade do ar; geração de empregos decentes; melhoria do planejamento urbano; e urbanização de favelas. Apoiamos ainda a gestão sustentável dos resíduos através da aplicação do princípio dos $3 R$ (reduzir, reutilizar e reciclar). (RIO+20, 2012, p. 26, tradução nossa).

Não obstante o registro do compromisso dos Chefes de Estado, são os líderes municipais que estão em posição diferenciada de responsabilidade para o planejamento e execução de ações que visem à consecução dos objetivos de desenvolvimento sustentável, na medida em se constituem como os principais provedores de infraestruturas e serviços, reguladores e mobilizadores de recursos e, principalmente, como articuladores da colaboração entre os diferentes atores que atuam nas cidades. Engajar os atores que atuam nas cidades ao redor dos objetivos do desenvolvimento sustentável é uma forma de estabelecer melhor posição no cenário competitivo do mundo contemporâneo (GUPTA, 2002; ESTY; WINSTON, 2009; DUNN, 2010; AHMAD; COLIN; AHMED, 2012). Cada combinação urbana de elementos é única, o que faz com que cada cidade seja também única, embora similaridades possam ser encontradas em seus sistemas de infraestrutura e serviços públicos e nas atividades econômicas e sociais. Essas diferenças entre as cidades também se fazem sentir no que diz respeito à disponibilidade de equipamentos públicos, colaborando para o incremento das capacidades de competição, diferenciação no provimento de serviços e facilidades, apetite para a inovação e para a adoção e implementação de novas práticas de gestão e de novas tecnologias. Esse diálogo entre singularidade e similaridade é determinante para o desenvolvimento das cidades, visto orientar também a recombinação das agendas e interesses dos atores tanto para seus objetivos particulares de competitividade quanto para os objetivos coletivos de qualidade de vida (MARKUSEN, 2006; JOHNSON, 2008; WINDEN, 2008; DIRKS; GURDGIEV; KEELING, 2010; SASSEN, 2010; TOPPETA, 2010; RASOOLIMANESH; BADARULZAMAN; JAAFAR, 2011; JONAS, 2012).

O desafio, então, está focalizado na possibilidade de construção de um novo modelo de realização de transações que são eminentemente financeiras, para um modelo que também considera, em igual escala, as questões ambientais e sociais (GUPTA, 2002; KATES; PARRIS; LEISEROWITZ, 2005; CRITTENDEN et al., 2010; ECCLES; PERKINS; SERAFEIM, 2012; ELKINGTON, 
2012; METCALF; BENN, 2013). Ao se constituírem, contudo, como os principais pontos de consumo ineficiente de recursos naturais, de criação de ofensores ao meio ambiente, de geração de diferenças sociais e de profundas necessidades de continuidade, as cidades atraem para si todas as atenções. As arenas de discussão sobre o desenvolvimento sustentável têm tomado as agendas de governos, empresas e academia, em todos os níveis de atuação. Isso inclui os esforços transnacionais para que problemas como combate à pobreza, oferta de serviços adequados de saúde, educação e segurança, preservação dos recursos naturais, principalmente a água, mobilidade e o próprio desenho do espaço urbano tenham soluções equilibradas sem, no entanto, incapacitar as cidades para a produção de riquezas e obtenção de desempenho econômico diferenciado (GUPTA, 2002; YOON; TELLO, 2009; PRATTIPATI, 2010; CRITTENDEN et al., 2010; DUNN, 2010; SASSEN, 2010; ELKINGTON, 2012).

De fato, as cidades são novas fronteiras para a criação de novos tipos de fontes geradoras de energia, métodos construtivos, infraestruturas e serviços ambientalmente sustentáveis. Evitar o desperdício de recursos financeiros por conta da ineficiência dos sistemas de transportes de cargas e de pessoas; reduzir as deficiências nos processos e tecnologias utilizados na antecipação a desastres naturais; reestruturar e revitalizar as zonas residenciais ocupadas por pessoas de baixa renda, assim como reaproveitar espaços industriais ou destinados a armazenagem e que estejam desativados ou não explorados; monitorar e manter as infraestruturas de geração e distribuição de energia e de água, incluindo o fomento a fontes alternativas de energia - eólica, solar - e reduzir problemas nos sistemas de abastecimento e armazenamento de água de chuva; promover polos de inovação e economia criativa, para além do fomento aos empreendimentos sociais; desenvolver programas de educação ambiental associados a ações de redução, reutilização e reciclagem de resíduos; e criar um ambiente de negócios favorável são ações que dependem em grande escala dos líderes municipais. Por meio delas, eles podem despertar a capacidade inovativa da cidade e evitar a retração nas atividades econômicas e o desaparecimento de postos de trabalho, enquanto constroem cidades mais resilientes (ALMEIDA, 2007; JOHNSON, 2008; MACHIBA, 2010; SASSEN, 2010; HAMMER et al., 2011; CADENA; DOBBS; REMES, 2012; SEELIGER; TUROK, 2013).

Sob essa perspectiva, conectar os negócios empresarias às questões da sustentabilidade urbana - a cidade que é gerenciada sob os princípios do desenvolvimento sustentável - pode representar uma oportunidade para que os líderes municipais se beneficiem das ideias e dos esforços de responsabilidade social empresarial e tragam, para suas iniciativas, a força e a experiência do setor privado, particularmente no que diz respeito ao planejamento estratégico, 
formação corporativa e aproveitamento de talentos, para além dos princípios de retorno sobre investimentos. Não se trata, por óbvio, de confundir o público com o privado, ou vice-versa, mas de estabelecer parcerias, na melhor forma da legislação vigente, capazes de promover as mudanças necessárias à sobrevivência das cidades. Líderes municipais devem reconhecer que, assim como quaisquer organizações, as cidades são ambientes complexos, interconectados por sistemas dinâmicos, que embarcam diferentes subsistemas econômicos, ambientais e sociais e entender os papéis e responsabilidades de cada ator é crucial para o desenvolvimento sustentável de suas cidades (ALMEIDA, 2007; METCALF; BENN, 2013).

Colocadas essas reflexões, fica evidente que a inovação para a sustentabilidade assume papel preponderante no contexto das cidades, uma vez que elas têm as condições necessárias para determinar as soluções para os problemas que lá surgem, aproveitando suas redes de informação para facilitar a comunicação e a educação dos atores para que se engajem no apoio e participação em programas ambientais e institucionais e incrementem o crescimento da consciência de todos os atores com relação à melhoria e preservação do lugar onde atuam e vivem (GUPTA, 2002; ALMEIDA, 2007; JOHNSON, 2008; HANSEN; GROSSE-DUNKER; REICHWALD, 2009; BARBIERI et al., 2010; SASSEN, 2010).

\section{UM CHAMAMENTO À AÇÃO PARA A GLOBALIZAÇÃO CONSCIENTE E RESPONSÁVEL}

O fenômeno da urbanização tem provocado intensas discussões sobre o papel das cidades no contexto econômico global, ao ponto de muitos estudiosos celebrarem o seu reflorescimento como uma rota viável para o impulsionamento do crescimento, desenvolvimento e prosperidade, explorando de forma crescente as capacidades de conhecimento, criatividade e inovação dos atores que nelas atuam (BRAY, 1993; SASSEN, 1998; MARKUSEN, 2006; SCOTT, 2006; LANDRY, 2008) e as transformando em chave para o desenvolvimento e prosperidade dos países (JOHNSON, 2008), passando a interagir com outras próximas, estimulando o capital humano, modernizando suas infraestruturas, privilegiando as diretrizes do desenvolvimento sustentável, de forma a incrementar sua projeção e competição no cenário global e determinando uma nova configuração do mundo capitalista (BRENNER, 1998; SCOTT et al., 2001; PASTOR; LESTER; SCOGGINS, 2009; QUIGLEY, 2009; HAMMER et al., 2011). Com isso, associar as tendências econômicas e sociais globais às características das cidades é de fundamental importância para que elas sejam entendidas como espaços-chave da economia, onde se presencia os efeitos da proximidade geográfica ou virtual, o acúmulo e o 
fluxo de capital, a expansão e concentração de determinados setores industriais e de serviços ou sua retração -, a dinâmica da oferta de trabalho, as controvérsias étnicas e de classes sociais, resultando em polarizações socioespaciais (FRIEDMANN, 1986; BRENNER, 1998; BOLLIER, 1998; SCOTT et al., 2001; CHASE-DUNN; JORGENSON, 2001; PARKINSON et al., 2004; SASSEN, 2005; COHEN, 2011). Sob as perspectivas de aumento da escala das transações de negócios em todas as suas formas, as cidades assumem um novo papel no cenário da economia global (SASSEN, 1998; SCOTT et al., 2001). Impulsionadas pelas novas formas que as atividades econômicas vêm assumindo, pelas possibilidades de colaboração e pelas necessidades de respostas às necessidades prementes dos atores, as cidades se posicionam como principal vetor da economia global, articulando a integração entre o local e o global, estimulando o crescimento de empresas que, por sua vez, impulsiona os complexos sistemas de prestação de serviços (BRENNER, 1998; SASSEN, 1998; SCOTT et al., 2001; SASSEN, 2005; HUANG; LEUNG; SHEN, 2007) e motivando a criação de novas estratégias e planos que visem à mitigação de problemas proporcionais à riqueza produzida e que afetam os atores em suas diferentes atividades (LANDRY, 2008; SCOTT et al., 2001).

Para Scott (2006),

As origens do desenvolvimento urbano e o crescimento na moderna sociedade urbana residem, antes de tudo, nas dinâmicas da produção econômica e do trabalho. Embora contestável, essa proposição é defensável. Essas dinâmicas governam o movimento das fortunas de cada área urbana individual, assim como contam de forma significativa para os resultados mais gerais de outras cidades no cenário global. Por certo, as cidades são sempre algo muito mais do que apenas acumulações nuas de capital e trabalho, pois elas são também espaços em que muitos outros tipos de fenômenos, sociais, culturais e políticos - acontecem (SCOTT, 2006, p. 2, tradução nossa).

Segundo Winden (2008), as cidades são permanentemente desafiadas a explorar seus ativos materiais e intelectuais, de forma a promover o desenvolvimento econômico e intensificar, por meio deles, vantagens competitivas. As cidades eficientes e produtivas geram os recursos necessários para a realização de investimentos em infraestrutura e serviços, reunindo as condições necessárias para promover melhorias na qualidade de vida das pessoas (QUIGLEY, 2009; JOHNSON, 2008). Portanto, a implementação de estratégias que focalizem o empreendedorismo e a atração de talentos é um fator crítico de sucesso para as cidades que buscam projeção no cenário global. Algumas cidades têm crescido mais do que outras, agindo como ímãs para a atração de talentos e investimentos em detrimento daquelas particularmente as menores ou as que estão encravadas em áreas rurais - que não conseguem 
desenvolver especializações ou mesmo se manter atualizadas para fazer frente às demandas das pessoas (WINDEN, 2008). As cidades integradas na dinâmica global desenvolvem posição vantajosa sobre outras que não estejam inseridas nessa dinâmica, podendo estabelecer ascensão e liderança sobre essas cidades periféricas. Se as empresas competem entre si em termos de produtos, serviços e seus respectivos padrões de qualidade e preço, as cidades competem entre si em termos de atratividade para investimentos privados, turismo, oferta de possibilidades para uma vida humana satisfatória - moradia, saúde, segurança, educação, lazer, cultura -, atração e disponibilidade de mão de obra qualificada e ambiente de negócios favorável (BOLLIER, 1998; STORPER, 1997; BEGG, 1999; FLORIDA, 2002; GOLGHER, 2008; DIRKS; GURDGIEV; KEELING, 2010; JONAS, 2012).

Os líderes municipais passam, então, a enfrentar o dilema entre o progresso de amplitude global e os clamores por sustentabilidade: encorajar o surgimento de um ambiente de negócios propício, capaz de atrair profissionais e sistemas educacionais de alto desempenho versus as exigências cada vez mais crescentes por preservação ambiental e justiça social. De fato, a expansão da atividade econômica nas cidades não significa, necessariamente, a expansão dos níveis de tráfego e congestionamento, desperdício ou gasto excessivo de energia e água ou mais poluição. De igual forma, a preservação do meio ambiente não significa, obrigatoriamente, redução ou a erradicação da atividade econômica. Isso torna claro o papel dos líderes municipais, porquanto são os principais responsáveis por determinar e dirigir a dinâmica urbana em direção à um futuro desejável: infraestrutura eficiente, serviços públicos de qualidade reconhecida, oportunidades de trabalho, lazer e cultura, para além do permanente aprimoramento das especializações profissionais e atividades econômicas da cidade. É fundamental que os líderes municipais compreendam que não há garantias de manutenção de suas posições nas hierarquias urbanas e que as atividades econômicas tradicionais de suas cidades estão sob permanente ataque daquelas que vislumbram atrair empresas e trabalhadores qualificados já estabelecidos, como já discutido por Markusen (2006).

Ao mesmo tempo em que travam competições tanto no âmbito doméstico quanto no âmbito internacional, as cidades se tornam alvo das empresas e pessoas que buscam novas oportunidades de negócios e oportunidades profissionais e sociais, respectivamente, potencializando os desafios para o poder público local, particularmente no que diz respeito à capacidade de entregar infraestrutura, serviços e governança adequados. Movimentações de pessoas e empresas que, outrora, se configuram com eventos potencialmente impraticáveis, atualmente fazem parte da dinâmica da sociedade. Os progressos nas relações multilaterais, 
associados aos avanços tecnológicos em transportes e comunicações, têm impulsionado o comércio e as transações financeiras, a movimentação de capital e de investimentos, a migração de pessoas de e para diferentes partes do globo, para além da criação e propagação de conhecimento. Essa dinâmica, que atravessa continentes, países e, principalmente, cidades tem influenciado o comportamento de governos, empresas, cidadãos e outros atores, exigindo que líderes, em todas as esferas da sociedade, formulem políticas e desenvolvam práticas que sejam eficientes para mitigar os riscos e potencializar as oportunidades advindos a globalização (SCOTT, 2006). No cenário da derrubada das fronteiras trazida pela globalização e da intensa aceleração da competição entre as cidades, a globalização permanece como tema de discussão, visto constituir uma importante força de organização de mercados e sistemas de produção, de competição além das fronteiras geográficas, impulsionando as cidades para outros níveis de relacionamento (STORPER, 1997; PARKINSON et al., 2004).

A despeito da perda de postos de trabalhos ou mesmo do desaparecimento de empresas ao redor globo, a globalização também trouxe novas oportunidades de especialização e novas formas de proximidade entre cidades, mercados e empresas, criando também outras possibilidades profissionais e sociais para as pessoas (FELDMAN; AUDRETSCH, 1999; BOSCHMA, 2005; HENDERSON, 2007). Muitas empresas de grande representatividade na economia de seus países, em todos os setores, passam a fazer parte, também, das economias dos países para onde dirigem seus esforços de internacionalização. Se, por um lado, esse movimento traz em si ameaças às empresas locais que oferecem produtos ou serviços similares, por outro lado representa a oportunidade para que outras formas de exploração econômica sejam exploradas, propiciando o desenvolvimento de uma nova cadeia de valor para a cidade que recebe aquelas. Mesmo mantendo suas sedes em seus países de origem, suas operações em outras geografias são capazes de fomentar a demanda por novas empresas de serviços, manufaturas e de infraestruturas. Ao apresentarem as condições minimamente necessárias em termos de infraestruturas e serviços públicos, para além de práticas aceitáveis de ambiente de negócios e de governança pública, para receber empresas de grande porte, as cidades se posicionam no cenário global de competição por novos investimentos e novas possibilidades de desenvolvimento e projeção. Viabilizar as interações entre diferentes perspectivas econômicas e sociais - comércio internacional, sistema educacional, turismo de negócios e de lazer, atividades culturais, mídia e até mesmo as possibilidades de interações religiosas - permite às cidades a possibilidade de empreender um ciclo virtuoso de prosperidade e maior capacidade de resistir aos desafios para a manutenção da posição conquistada, qualificando-se como 
socioeconomia - local, regional ou global - e cumprindo o objetivo de utilidade para as forças do mundo capitalista (STORPER, 1997; HUANG; LEUNG; SHEN, 2007).

As cidades estão em constante mudança, alterando seus padrões de inovação e de dinâmicas econômica e social, criando riquezas e desenvolvendo capital humano, transformando-se em pilares da economia local, regional e global, não se configurando como lugares rígidos e incapazes de se adequar às tendências mundiais, conforme já caracterizadas por Friedmann (1986), Brenner (1998), Scott et al. (2001) e posteriormente por Sassen (2005). Graças à derrubada das fronteiras decorrente da globalização, algumas cidades se posicionaram de forma mais propícia ao desenvolvimento de negócios, atraindo para si volumosos investimentos e se tornaram referências mundiais, sobrepondo-se, em muitos casos, aos próprios países onde se localizam e com influência significativa no cenário econômico de outras cidades e outros países. Muitas dessas cidades globais têm orientado e reconfigurado o modelo econômico mundial, determinando, inclusive, uma nova distribuição territorial; elas atraem para si e para outras tantas cidades em proximidade geográfica ou virtual, novos fluxos de capitais, conhecimento, ciência, tecnologia e inovação, estimulando e incrementando as possibilidades de interação (BRENNER, 1998; SASSEN, 2005; CASTELLS, 2012).

\section{UM CHAMAMENTO À AÇÃO PARA A GOVERNANÇA URBANA}

Segundo Sassen (2010), as cidades estão cada vez mais expostas às exigências globais de governança, visto que elas devem enfrentar esses desafios muito antes que os governos dos países tenham assinado qualquer acordo internacional ou mesmo aprovado leis específicas para tratar o assunto.

Os avanços tecnológicos recentes, particularmente aqueles notados nas tecnologias de informação e comunicação, têm conectado governos, empresas e as pessoas em qualquer lugar e a qualquer tempo. Conhecimento e informação são um novo paradigma de socialização, permitindo que cidadãos possam, quase que em tempo real, saber sobre o que possa afetar suas vidas, direta ou indiretamente. O mesmo vale para governos, empresas e quaisquer outras organizações próprias da dinâmica urbana. Em face de tais cenários, novamente os líderes locais são desafiados a constituir novos modelos de governança que visem não somente os interesses governamentais ou político-partidários, mas também o envolvimento de todos os atores no desenho e concretização de planos que garantam o permanente estreitamento de relações e as condições necessárias para o progresso por todos almejado (RASOOLIMANESH; 
BADARULZAMAN; JAAFAR, 2011; AHMAD; COLIN; AHMED, 2012).

Para Winden (2008),

A governança urbana não é uma questão que diz respeito apenas aos atores urbanos. Cada vez mais, torna-se claro que as políticas regionais e nacionais têm profundo impacto no nível urbano (...) e os governos nacionais têm reconhecido as cidades como motores do crescimento econômico dos países e buscam novas maneiras de habilitá-las para tal responsabilidade (WINDEN, 2008, p. 198, tradução nossa).

A Organização para a Cooperação e Desenvolvimento Econômico (OCDE) define governança pública como "o conjunto de arranjos formais e informais que determinam como as decisões públicas são tomadas e executadas, a partir da perspectiva da manutenção dos valores constitucionais do país, em face de problemas, atores e ambientes. " (OCDE, 2005, p.16, tradução nossa).

Em todas as áreas da gestão pública, a governança deve ser aprimorada, de forma que os princípios de responsabilidade objetiva, ética, idoneidade, transparência, eficiência, eficácia, sustentabilidade e observância às leis sejam uma constante e estejam sempre à prova dos atores locais e de outros interessados sobre como a cidade é gerenciada. Tal como em outras organizações, o setor público também estabelece e mantém claras ligações entre os investimentos, o desenvolvimento e as práticas de boa governança. No setor público, entretanto, o desafio é relacionar os princípios de governança às mudanças sociais globais. Melhores níveis de governança, sustentados por leis e normas conhecidas e devidamente transparentes e comunicadas, criam flexibilidade, credibilidade e confiança, de forma a realizar o desenvolvimento econômico sustentável e a equidade e justiça social.

Para Klink (2009),

As novas formas de governança metropolitana que vêm surgindo como tendência mundial, precisam provar a sua efetividade em termos de equacionar os verdadeiros problemas metropolitanos. Ou seja, além de se caracterizarem pela legitimidade política (pois são embasadas no próprio protagonismo dos atores públicos e privados), as novas formas de governança regional e metropolitana deveriam reduzir os congestionamentos, a poluição ambiental e proporcionar um conjunto de projetos voltados para a competitividade sistêmica das cadeias produtivas regionais, para mencionar alguns dos desafios (KLINK, 2009, p.223).

Nessa altura, a reflexão sobre as desigualdades econômicas, políticas e sociais que afetam os cidadãos também podem mantê-los fora do cenário de participação na tomada de decisões e dos processos legislativos que os afetam direta ou indiretamente. Essas desigualdades podem servir de sustentação para que agentes públicos menos afeitos à ética e à moral se privilegiem financeiramente e até mesmo moralmente desses cidadãos, provocando 
ineficiência na prestação de serviços, destinação equivocada de recursos públicos e até mesmo corrupção, levando a confiança no poder público a níveis inaceitáveis. Dessa forma, as cidades que almejam constituir uma sociedade da informação e do conhecimento, que busquem a excelência em ciência, tecnologia e inovação, que tenham o desenvolvimento sustentável como objetivo inequívoco, que fomentem o crescimento e o desenvolvimento com vistas à prosperidade de todos os atores, que sejam capazes de competir no cenário econômico com base em princípios e valores aceitáveis por todos os mercados e, não menos importante, que tenham a visão da sua projeção no mundo globalizado, devem buscar a implementação de uma nova visão de governança pública e urbana. Governança essa que extrapole os limites da burocracia da administração pública e estenda suas mãos a todos os atores, particularmente aos menos favorecidos, de sorte a que todos possam participar dos destinos da cidade onde atuam ou vivem.

Como afirmado por Xavier e Guimarães (2016),

Governar as cidades e as metrópoles na atualidade, com a participação ampla dos atores, pode estar relacionada à incorporação de vantagens que os paradigmas econômicos atuais podem oferecer ao sistema de convivência urbana. Muito do que se afirma em torno da lentidão dos serviços e das falhas da burocracia, que emperram as decisões da administração pública e consequente prestação de serviços eficientes, está relacionado à falta de comunicação e integração institucional. (XAVIER; GUIMARÃES, 2016, p. 1370).

Colocadas essas perspectivas, evidencia-se que a natureza da governança urbana deve primar não somente pelos aspectos legais e institucionais, mas também pelo reconhecimento que engajamento dos atores é fundamental para o estabelecimento de boas práticas de governança. Fundamental também são o reconhecimento da necessidade de fomento à intensificação do relacionamento governo-cidadãos e entre os cidadãos, a clara definição e implementação de papéis e responsabilidades para as entidades governamentais, não governamentais e empresas; o estabelecimento de processos e práticas que garantam o diálogo entre o governo e o engajamento da sociedades ao redor dos objetivos da sustentabilidade urbana e, não menos importante, a disponibilidade de recursos humanos, financeiros e de informações.

\section{CONSIDERAÇÕES FINAIS}

No curso desse trabalho propôs-se a realização de uma reflexão acerca do fenômeno da urbanização e das exigências que se interpõem aos gestores públicos e aos demais atores 
sociais com vistas ao enfrentamento dos desafios advindos de tal fenômeno.

Discutiu-se que tal fenômeno tem provocado intensas discussões sobre o papel das cidades no contexto econômico global, ao ponto de muitos estudiosos celebrarem o seu reflorescimento como uma rota viável para impulsionar o crescimento, desenvolvimento e prosperidade, explorando de forma crescente as capacidades de conhecimento, criatividade e inovação dos atores que nelas atuam e as transformando em chave para o desenvolvimento e prosperidade dos países. O cenário global, exigente por diferentes níveis de especialização e caracterizado por grande diversidade de mercados, faz com que as cidades se configurem como nós fundamentais e agentes críticos para o desenvolvimento e crescimento econômico dos países onde se localizam.

Refletiu-se que as novas configurações urbanas vão se conformando como canais de informação e conhecimento, reformulando suas características produtivas e impelindo as cidades a assumirem um papel próprio dos empreendedores. As cidades, em qualquer estágio de desenvolvimento e de urbanização em que se encontrem, em qualquer região do globo ou de qualquer tamanho que sejam, estão expostas às condições de crescimento econômico, instabilidades sociais, pressões por sustentabilidade ambiental e, em maior ou menor escala, às regras impostas pelas dinâmicas da globalização, os efeitos das mudanças climáticas e as restrições à disponibilidade dos recursos naturais, técnicos, humanos e financeiros. A habilidade que elas têm ou podem desenvolver para enfrentar as dificuldades sociais, ambientais e econômicas, ao mesmo tempo em que se adaptam à evolução das circunstâncias globais, é crucial para a criação de cidades robustas, resilientes e aprazíveis, capazes de competir e ao mesmo tempo cooperar entre si para o desenvolvimento de novas oportunidades e formas alternativas de alcançar a prosperidade.

Como organizações, as cidades, ao longo do tempo, vão se moldando para atender aos novos modelos sociais e o inverso é de igual forma verdadeiro: novos modelos sociais vão determinando o desenho das cidades, prenunciando um ciclo ininterrupto de demandaatendimento no espaço urbano.

Assim, não obstante os desafios impostos pela concentração de pessoas em ambientes urbanos, as possibilidades de colaboração entre governos, iniciativa privada e academia tornam-se críticas para viabilizar o compartilhamento de conhecimentos, capaz de produzir soluções inovadoras que visem o estabelecimento de estratégias para o desenvolvimento econômico e a geração de oportunidades de prosperidade para além dos limites institucionais e geográficos. Essa colaboração, participativa e baseada no compartilhamento de informações 
sobre as razões para fazer, expectativas de investimentos e resultados esperados, é um fator crítico para que o caminho de qualquer iniciativa seja percorrido com a atribuição adequada de prioridades, atenção às reais necessidades dos atores e transparência. Essa colaboração é imperiosa para que o processo de inovação seja apropriadamente articulado.

Configurar-se como uma cidade inteligente é resultado de um processo evolutivo e transformacional, que demanda tempo e investimentos e não apenas o resultado de uma ação de implantação de tecnologias isoladas: a implantação de um centro de comando e controle ou a distribuição de acesso livre e gratuito à internet, embora de valor para as cidades, não asseguram à cidade a qualificação de cidade inteligente. Sob essa perspectiva, as cidades devem se preparar para que a mudança seja revolucionária, porquanto vão introduzir, em algum momento, tecnologias de última geração e que funcionam de maneira nova para muitos operadores e atores das cidades e não deveriam ser adotadas e implementadas em detrimento de outras menos complexas, mas de maior importância para a eficiência da gestão pública e de maior reconhecimento pelos atores. As cidades precisam considerar o capital humano necessário e disponível, estimulando o trabalho colaborativo interagências no âmbito local e com outros níveis de governo, com a academia, a iniciativa privada e organizações não governamentais -, para que as necessidades sejam avaliadas e as melhores decisões sejam tomadas, levando em conta os sistemas socioeconômicos em que se baseiam e as interações regionais das quais fazem parte. Cabe ao poder público, então, analisar, decidir e planejar ações que sejam fundamentais, e, como consequência, o que deve ser lançado, mantido ou expandido para que o objetivo da cidade inteligente seja alcançado.

\section{REFERÊNCIAS}

AHMAD, W.; COLIN, L. S.; AHMED, T. Strategic thinking on sustainability: challenges and sectoral roles. Environment, Development and Sustainability, v. 14, n. 1, p. 67-83, 2012.

AL-HADER, M.; RODZI, A. The smart city infrastructure development \& monitoring. Theoretical and Empirical Researches in Urban Management, v. 4, n. 2, p. 87-94, 2009.

ALLWINKLE, S; CRUICKSHANK, P. Creating smart-er cities: an overview. Journal of Urban Technology, v. 18, n. 2, p. 1-16, 2011.

ALMEIDA, F. Os desafios da sustentabilidade: uma ruptura urgente. Rio de Janeiro: Elsevier, 2007.

BAKICI, T.; ALMIRALL, E.; WAREHAM, J. A Smart City Initiative: The Case of Barcelona. Journal of 
the Knowledge Economy, v. 2, n. 1, p. 1-14, 2012.

BARBIERI, J. C. et al. Inovação e sustentabilidade: novos modelos e proposições. RAE, v. 50, n. 2, p. 146-154, 2010.

BARNES, W. R. Governing cities in the coming decade: the democratic and regional disconnects. Public Administration Review, n.70, p. 137-144, 2010.

BARRIONUEVO, J. M.; BERRONE, P.; RICART, J. E. Smart Cities, Sustainable Progress. IESE Insight Review, v. 14, p. 50-57, 2012.

BATAGAN, L. Smart cities and sustainability models. Informatica Economica, v. 15, n. 3, p. 80-87, 2011.

BATHELT, H.; MALMBERG, A.; MASKELL, P. Clusters and knowledge: local buzz, global pipelines and the process of knowledge creation. Progress in Human Geography, v. 28.1, p. 31-56, 2004.

BEGG, I. Cities and competitiveness. Urban Studies, v. 36, n. 5, p. 795-810, 1999.

BOLLIER, D. How smart growth can stop sprawl: a fledgling citizen movement expands. A briefing guide for funders. Washington D.C: Essential Books, 1998.

BOSCHMA, R. A. Proximity and innovation: a critical assessment. Regional Studies, v. 39, n. 1, p. 61-74, 2005.

BOYKO, C. T. et al. Addressing sustainability early in the urban design process. Management of Environmental Quality - Bradford, v. 17, n. 6, p. 689-706, 2006.

BRAY, P.M. The new urbanism: celebrating the city. Places, v. 8, n.4, p.56-65, 1993.

BRENNER, N. Global cities, glocal states: global city formation and state territorial restructuring in contemporary Europe. Review of International Political Economy, v. 5, n. 1, p. 1-37, 1998.

CADENA, A.; DOBBS, R.; REMES, J. The growing economic power of cities. Journal of International Affairs, v. 65, n. 2, p. 1-17, 2012.

CANTON, J. The extreme future of megacities. Significance, v. 8, n. 2, p. 53-56, 2011.

CARAGLIU, A.; DEL BO, C.; NIJKAMP, P. Smart Cities in Europe. Journal of Urban Technology, v. 18, n. 2, p. 65-82, 2011.

CASTELLS, M. A sociedade em rede. 6. ed. São Paulo: Paz e Terra, 2012.

CATS-BARIL, W. L.; THOMPSON, R. L. Managing information technology projects in the public sector. Public Administration Review, v. 55, n. 6, p. 559-66, 1995.

CHASE-DUNN, C.; JORGENSON, A. Regions and interaction networks: a world-system perspective. UC Riverside: The Institute for Research on World-Systems, 2001. Disponível em http://escolarship.org/uc/item/65d7k1rz. Acesso em: 28 jan. 2013. 
CHEN, T. M. Smart Grids, Smart Cities Need Better Networks [Editor's Note]. IEEE Network, v. 24, n. 2, p. 2-3, 2010.

CHOURABI, H. et al.. Understanding smart cities: an integrative framework. In: HAWAll INTERNATIONAL CONFERENCE ON SYSTEM SCIENCES, 45th., 2012, Hawaii. Anais eletrônicos... Albany: Center for Technology in Government, 2012. p. 2289-2297. Disponível em http://goo.gl/rt6WoP. Acesso em: 14 dez. 2014.

COHEN, M. P. Cities in times of crisis: the response of local government in light of the global economic crisis - the role of the formation of humam capital, urban innovation and strategic planning. Working Paper 2011-01. Disponível em http://escolarship.org/uc/item/3432p4rb. Acesso em: 28 jan. 2013.

CORIAT, B.; DOSI, G. The nature and accumulation of organizational competences/capabilities. Revista Brasileira de Inovação, v. 1, n. 2, p. 275-326, 2002.

CRETU, L-G. Smart Cities Design using Event-driven Paradigm and Semantic Web. Informatica Economica, v. 16, n. 4, p. 57-67, 2012.

CRITTENDEN, V. L. et al. Market-oriented sustainability: a conceptual framework and propositions. Journal of the Academy of Marketing Science, n. 39, p. 71-85, 2010.

DAWES, S. S. et al.. Making smart IT choices: understanding value and risk in government IT investments. Albany, Nova lorque: Center for Technology in Government, 2004. Disponível em http://www.ctg.albany.edu/publications/guides/smartit2/smartit2.pdf. Acesso em: 15 jul. 2012.

DIRKS, S.; GURDGIEV, C.; KEELING, M. Smarter cities for smarter growth. How cities can optimize their systems for the talent-based economy. 2010. IBM Institute for Business Value: Executive Report. Disponível em http://goo.gl/GafSjd. Acesso em: 21 set. 2012.

DOGDSON, M.; GANN, D. Technological Innovation and Complex Systems in Cities. Journal of Urban Technology, v. 18, n. 3, p. 101-113, 2011.

DUNN, B. P. Tracing the path of sustainable development through major international conferences: a brief history and overview of sustainable development 1964-2002. 2010. 93 p. Dissertação (Mestrado em Artes) - University of North Texas, Denton (Texas-USA).

DURANTON, G.; PUGA, D. Diversity and specialization in cities: why, where and when does it matter? Research Papers in Environmental and Spatial Analysis, n. 56, p. 1-45, London: 1999. Disponível

em http://www.Ise.ac.uk/geographyAndEnvironment/research/Researchpapers/rp56.pdf. Acesso em: 05 jun. 2012.

DUTTA, S. et al. The global innovation index 2011: accelerating growth and development. Fontainebleau: INSEAD, 2011.

The global information technology report 2009-2010: world economic forum. Genebra: SRO-Kundig, 2010.

ECCLES, R.G.; PERKINS, K.M.; SERAFEIM, G. How to become a sustainable company. MIT Sloan 
Management Review, v.53, n. 4, p. 42-50, 2012.

EGER, J. M. Smart growth, smart cities, and the crisis at the pump a worldwide phenomenon. IWays -The Journal of E-Government Policy and Regulation, v. 32, n. 1, p. 47-53, 2009.

EKINS, P. Eco-innovation for environmental sustainability: concepts, progress and policies. International Economics and Economic Policy, v. 7, n. 2-3, p. 267-290, 2010.

ELKINGTON, J. Sustentabilidade, canibais com garfo e faca. São Paulo: M. Books do Brasil, 2012.

ETZKOWITZ, H. The triple helix of university-industry-government: implications for policy and evaluation. Working Paper, n. 11, p. 1-16, 2002. Disponível em http://www.sister.nu/pdf/wp_11.pdf. Acesso em: 20 mai. 2014.

EVANS, G. Creative cities, creative spaces and urban policy. Urban Studies Journal, v. 46, n.5-6, p. 1003-1040, 2009.

FEENBERG, A. Racionalização Subversiva: tecnologia, poder e democracia. In: NEDER, R.T. (org) A teoria crítica de Andrew Feenberg: racionalização democrática, poder e tecnologia. Brasília: Observatório do Movimento pela Tecnologia Social na América Latina / CDS / UnB / Capes, 2010. cap. 2. p. 69-95.

FELDMAN, M. P.; AUDRESTSCH, D. B. Innovation in cities: science-based diversity, specialization and localized competition. European Economic Review, n. 43, p. 409-429, 1999.

FLORIDA, R. Bohemia and economic geography. Journal of Economic Geography, n. 2, p. 55-71, 2002.

FRIEDMANN, J. The world city hypothesis. Development and Change, n. 17, p. 69-83, 1986.

GAWEL, A. Entrepreneurship and sustainability: do they have anything in common? The Poznan University of Economics Review, v. 12, n. 1, p. 5-16, 2012.

GIFFINGER, R. et al.. Smart Cities: Ranking of European Medium-sized Cities. Vienna: Centre of Regional Science, 2007. Disponível em http://goo.gl/CmqVmm. Acesso em: 26 fev. 2013.

GIFFINGER, R.; HAINDLMAIER, G. Smarter cities ranking: an effective instrument for the positioning of cities? ACE: Architecture, City and Environment, n. 12, p. 7-25, 2010.

GLAESER, E. L.; SAIZ, A. The Rise of the Skilled City. Working Paper 10191, 2003. Disponível em http://www.nber.org/papers/w10191. Acesso em: 08 mai. 2015.

GOLGHER, A. B. As cidades e a classe criativa no Brasil: diferenças espaciais na distribuição de indivíduos qualificados nos municípios brasileiros. Revista Brasileira de Estudos de População, v. 25, n. 1, p. 109-129, 2008.

GUAN, L. Smart Steps To A Battery City. Government News, v. 32, n. 2, p. 24-27, 2012.

GUPTA, J. Global sustainable development governance: institutional challenges from a 
theoretical perspective. International Environmental Agreements: Politics, Law and Economics, v. 2, n. 4, p. 361-361, 2002.

HALL, P. Creative cities and economic development. Urban Studies, v. 37, n. 4, p. 639-649, 2000.

HALL, R. E. et al.. The vision of a smart city. In: PROCEEDINGS OF THE 2nd INTERNATIONAL LIFE EXTENSION TECHNOLOGY WORKSHOP ANNUAL INTERNATIONAL CONFERENCE ON DIGITAL GOVERNMENT RESEARCH. Anais eletrônicos... Upton: Brookhaven National Laboratory. 2000. Disponível em http://goo.gl/JjZ7TO. Acesso em: 15 ago. 2012.

HAMMER, S. et al. Cities and green growth: a conceptual framework. OECD Regional Development Working Papers 2011-08, 2011. OECD Publishing. Disponível em http://dx.doi.org/10.1787/5kg0tflmzx34-en. Acesso em: 04 set. 2012.

HANSEN, E. G.; GROSSE-DUNKER, F.; REICHWALD, R. Sustainability innovation cube - a framework to evaluate sustainability-oriented innovations. International Journal of Innovation Management, v.13, n. 4, p. 683-713, 2009.

HARRISON, C. et al.. Foundations for Smarter Cities. IBM Journal of Research and Development, v. 54, n. 4, p. 1-16, 2010.

HARRISON, C.; DONNELLY, I. A. A theory of smart cities. White Paper, 2011. Disponível em http://journals.isss.org/index.php/proceedings55th/article/viewFile/1703/572. Acesso em: 09 jun 2012.

HARTLEY, J. Innovation in governance and public services: past and present. Public Money \& Management, v. 25, n. 1, p. 27-34, 2005.

HENDERSON, H. Além da globalização: modelando uma economia global sustentável. São Paulo: Cultrix, 2007.

HERNÁNDEZ-MUÑOZ, J. M. et al. Smart cities at the forefront of the future internet. Lecture Notes in Computer Science, n. 6656, p. 447-462, 2011.

HUANG, Y.; LEUNG, Y.; SHEN, J. Cities and Globalization: An International Cities Perspective. Urban Geography, v. 28, n. 3, p. 209-231, 2007.

IBGE - INSTITUTO BRASILEIRO DE GEOGRAFIA E ESTATÍSTICA. Censo demográfico de 2010. Disponível em http://www.ibge.gov.br/home/estatistica/ populacao/censo2010/default.shtm. Acesso em: 21 fev. 2016.

JOHNSON, B. Cities, systems of innovation and economic development. Innovation: Management, Policy \& Practice, v. 10, n. 2-3, p. 146-155, 2008.

JONAS, A. E. G. Region and place: regionalism in question. Progress in Human Geography, v. 36, n. 2, p. 263-272, 2012.

KANTER, R. M.; LITOW, S. S. Informed and interconnected: a manifesto for smarter cities. 
Harvard Business School General Management Unit, Working Paper, 9-141, p. 1-27, 2009. Disponível em http://goo.gl/9MLJOu. Acesso em: 14 ago. 2014.

KATES, R. W.; PARRIS, T. M.; LEISEROWITZ, A. A. What is sustainable development? Environment: Science and Policy for Sustainable Development, v. 47, n. 3, p. 8-21, 2005.

KLINK, J. Regionalismo e reestruturação urbana: uma perspectiva brasileira de governança metropolitana. Revista Educação, v. 32, n. 2, p. 217-226, 2009.

KOMNINOS, N. Intelligent Cities: Variable Geometries of Spatial Intelligence. Intelligent Buildings International, v. 3, n. 3, p. 172-188, 2011.

The architecture of intelligent cities; integrating human, collective, and artificial intelligence to enhance knowledge and innovation. IN: 2nd INTERNATIONAL CONFERENCE ON INTELLIGENT ENVIRONMENTS, 2006. Anais eletrônicos... Athens: Institution of Engineering and Technology. Disponível em http://goo.gl/hHBnR3. Acesso em: 10 jun. 2014.

KOURTIT, K.; NIJKAMP, P. Smart Cities in the Innovation Age. Innovation: European Journal of Social Science Research, v. 25, n. 2, p. 93-95, 2012.

KOURTIT, K.; NIJKAMP, P.; ARRIBAS, D. Smart Cities in Perspective - A Comparative European Study by Means of Self-organizing Maps. Innovation: European Journal of Social Science Research, v. 25, n. 2. P. 229-246, 2012.

KULKKI, S. Cities for Solving Societal challenges: Towards Human-centric Socio-economic Development? Interdisciplinary Studies Journal, v. 3, n. 4, p. 8-14, 2014.

LANDRY, C. The Creative City: a toolkit for urban innovators. London: Earthscan, 2008.

LAZAROIU, G. C.; ROSCIA, M. Definition Methodology for the Smart Cities Model. Energy, v. 47, n. 1, p. 326-332, 2012.

LEE, J. H.; PHAAL, R.; LEE, S.-H. An integrated service-device-technology roadmap for smart city development. Technological Forecasting and Social Change, v. 80, n. 2, p. 286-306, 2013.

LEYDESDORFF, L.; DEAKIN, M. The triple helix model and the meta-stabilization of urban technologies. Journal of Urban Technology, v. 18, n. 2, p. 53-63, 2011.

LOMBARDI, P. et al.. An advanced triple-helix network model for smart cities performance. Research Memorandum 2011-45, 2011. Disponível em http://dare.ubvu.vu.nl/bitstream/handle/1871/24007/rm\%202011-45.pdf?sequence=1. Acesso em: 22 abr. 2015.

MACHIBA, T. Eco-innovation for enabling resource efficiency and green growth: development of an analytical framework and preliminary analysis of industry and policy practices. International Economics and Economic Policy, n. 7, p. 357-370, 2010.

MARCEAU, J. Innovation in the City and Innovative Cities. Innovation : Management, Policy \& Practice, v. 10, n. 2/3, p. 136-145, 2008.

MARKUSEN, A. The distinctive city: divergent patterns in growth, hierarchy and specialization. 
Urban Studies, v. 43, n. 8, p. 1301-1323, 2006.

MARSAL-LLACUNA, M. L.; COLOMER-LLINÀS, J.; MELÉNDEZ-FRIGOLA, J. Lessons in urban monitoring taken from sustainable and livable cities to better address the Smart Cities initiative. Technological Forecasting and Social Change, v. 90, p. 611-622, 2015.

MEIER, W. J.; ULFERTS, G. W.; HOWARD, T. L. Transforming city governments through IT. The Review of Business Information Systems, v. 15, n. 4, p. 1-3, Fourth Quarter, 2011.

METCALF, L.; BENN, S. Leadership for sustainability: an evolution of leadership ability. Journal of Business Ethics, v. 112, n. 3, p. 369-384, 2013.

NAM, T.; PARDO, T. A. Conceptualizing smart city with dimensions of technology, people and institutions. In: ANNUAL INTERNATIONAL CONFERENCE ON DIGITAL GOVERNMENT RESEARCH: DIGITAL GOVERNMENT INNOVATION IN CHALLENGING TIMES, 12th, 2011, Washington. Anais eletrônicos... New York: ACM, 2011a. Disponível em http://www.ctg.albany.edu/publications/journals/dgo_2011_smartcity/dgo_2011_smartcity.pdf . Acesso em: 10 jun. 2012.

Smart city as urban innovation: focusing on management, policy and context. In: INTERNATIONAL CONFERENCE ON THEORY AND PRACTICE OF ELECTRONIC GOVERNANCE (ICEGOV2011), 5th, 2011, Tallin. Anais eletrônicos... New York: ACM, 2011b. Disponível em http://www.ctg.albany.edu/publications/journals/ icegov_2011_smartcity. Acesso em: 20 jun. 2012.

OCDE. Modernizing government: The Way Forward, 2005. Disponível em http://goo.gl/8wwajg . Acesso em: 12 nov 2014.

ODENDAAL, N. Information and communication technology and local governance: understanding the difference between cities in developed and emerging economies. Computers, Environment and Urban Systems, v. 27, n. 6, p. 585-607, 2003.

ONU - ORGANIZAÇÃO DAS NAÇÕES UNIDAS. World Urbanization Prospects: Revision 2014 Highlights. 2014. Disponível em http://goo.gl/ZaXUnE . Acesso em: 05 abr. 2015.

PALLOT, M. et al. Future internet and LivingLab research domain landscapes: filling the gap between technology push and application pull in the context of smart cities. In: ECHALLENGES e-2011 CONFERENCE PROCEEDINGS, 2011, Istambul. Anais eletrônicos... Thessalonik: URENIO Urban and Regional Innovation Research, 2011. Disponível em http://www.urenio.org/wpcontent/uploads/2008/11/2011-eChallenges-Nr-200-Future-Internet-and-Living-Labs-

Published.pdf. Acesso em: 14 ago. 2012.

PARKINSON, M. et al.. Competitive european cities: where do the core cities stand? London: Her Majesty's Stationery Office, 2004.20 Disponível em http://www.eukn.org/dsresource?objectid=149079. Acesso em: 20 jun. 2012.

PASTOR, M.; LESTER, T. W.; SCOGGINS, J. Why regions? Why now? Who cares? Journal of Urban Affairs, v. 31, n. 3, p. 269-296, 2009.

$\mathrm{POL}, \mathrm{O}$. et al.. Integration of centralized energy monitoring specifications into the planning process of a new urban development area: a step towards smart cities. e \& i Elektrotechnik und 
Informationstechnik, v. 129, n. 4, p. 258-264, 2012.

POTTS, J.; KASTELLE, T. Public sector innovation research: what's next? Innovation: Management, Policy \& Practice, v. 12, n. 2, p. 122-137, 2010.

PRATTIPATI, S. N. Sustainability and the role of information and communications technologies. Business Renaissance Quarterly, v. 5, n. 2, p. 23-40, 2010.

QUIGLEY, J. M. Urbanization, agglomeration and economic development. In: SPENCE, M. et al. Urbanization and growth. Washington, DC: Commission on Growth and Development, 2009, p. 115-132.

RASOOLIMANESH, S. M.; BADARULZAMAN, N.; JAAFAR, M. Achievement to sustainable urban development using city development strategies: a comparison between cities alliance and the World Bank definitions. Journal of Sustainable Development, v. 4, n. 5, p. 151-166, 2011.

RIO+20 - UNIÃO DAS NAÇÕES UNIDAS. The future we want. 2012. Disponível em http://goo.gl/ZUiU1D . Acesso em: 02 ago. 2014.

SASSEN, S. As cidades na economia mundial. São Paulo: Studio Nobel, 1998.

SASSEN, S. Cities are at the center of our environmental future. Revista de Ingeniería, n. 31, p. 72-83, 2010. Disponível em http://www.redalyc.org/articulo.oa?id=121015012003. Acesso em: 05 jan. 2015. 2005.

The global city: introducing a concept. Brown Journal of World Affairs, v. 11, n. 2, p. 27-43,

SCHAFFERS, H. et al. Smart cities and the future internet: towards cooperation frameworks for open innovation. Lecture Notes in Computer Science, n. 6656, p. 431-446, 2011.

SCOTT, A. J. Creative cities: conceptual issues and policy questions. Journal of Urban Affairs, v. 28, n. 1, p. 1-17, 2006.

Global city-regions: an overview. In: SCOTT, A. J. (ed). Global city-regions: trends, theory, policy. Oxford: Oxford University Press, 2001. p. 11-30.

SEELIGER, L.; TUROK, I. Towards Sustainable Cities: Extending Resilience with Insights from Vulnerability and Transition Theory. Sustainability, v. 5, p. 2108-2128, 2013.

STORPER, M. The city: Centre of economic reflexivity. The Service Industries Journal, v. 17, n. 1, p. 1-27, 1997.

TEECE, D. J.; PISANO, G.; SHUEN, A. Dynamic Capabilities and Strategic Management. Strategic Management Journal, v. 18, n. 7, p. 509-533, 1997.

THITE, M. Smart Cities: Implications of Urban Planning for Human Resource Development. Human Resource Development International, v. 14, n. 5, p. 623-631, 2011.

TOPPETA, D. The Smart City Vision: How Innovation and ICT Can Build Smart, "Livable", Sustainable Cities. 2010. Disponível em http://goo.gl/wXJIK9. Acesso em: 12 fev. 2012. 
UN-HABITAT. State of the world's cities report 2012/2013: prosperity of cities. 2012. Disponível em http://goo.gl/cyJPwj. Acesso em: 06 out. 2014.

VELOSA, A. et al. Smart Cities Are the New Revenue Frontier for Technology Providers. 2011. Disponivel em https://www.gartner.com/doc/1615214/market-trends-smart-cities-new. Acesso em: 20 jun. 2013.

WASHBURN, D. et al. Helping CIOs Understand "Smart City" Initiatives: Defining the Smart City, Its Drivers, and the Role of the ClO. Cambridge: Forrester Research, 2010. Disponível em http://goo.gl/fT4FYd. Acesso em: 18 jun. 2012.

WINDEN, W. van. Urban governance in the knowledge-based economy: Challenges for different city types. Innovation: Management, Policy \& Practice, n. 10, p. 197-210, 2008

WOLFE, D. A.; BRAMWELL, A. Innovation, creativity and governance: social dynamics of economic performance in city-regions. Innovation: Management, Policy \& Practice, v. 10, n. 2-3, p. 170-182, 2008.

WOLFRAM, M. Deconstructing smart cities: an intertextual reading of concepts and practices for integrated urban and ICT development. Proceedings REAL CORP 2012 Tagungsband, p. 171-181, 2012.

XAVIER, Y. M. de A.; GUIMARÃES, P. B. V.. Smart Cities e Direito: conceitos e parâmetros de investigação da governança urbana contemporânea. Revista de Direito da Cidade, v. 8, n. 4, p. 1362-1380, 2016.

YOON, E.; TELLO, S. Corporate social responsibility as a driver of sustainable innovation: greening initiatives of leading global brands. Competition Forum, v. 7, n. 2, p. 290-294, 2009.

ZYGIARIS, S. Smart City Reference Model: Assisting Planners to Conceptualize the Building of Smart City Innovation Ecosystems. Journal of the Knowledge Economy, v. 4, n. 2, p. 217-231, 2013.

Trabalho enviado em 22 de fevereiro de 2017.

Aceito em 06 de abril de 2017. 